\section{Theoretical pharmacokinetic advantages and methodological flaws: glargine is not superior to NPH insulin in children with type 1 diabetes mellitus}

José Miguel Dora' ${ }^{1,2}$, Rafael S. Scheffel

To the Editor,

We have read with great interest the recent article by Rollin and collaborators (1) concerning the use of glargine and NPH insulin in children (0-8 years old) with type 1 diabetes mellitus (TIDM). We would like to comment on the context which it emerges from, on aspects about the study design, and on how data is presented and interpreted. We believe that taking our comments into account would substantially change the interpretation drawn from this study.

Glargine is an insulin analog that, in theory, has pharmacokinetic advantages when compared to NPH insulin (2). Unfortunately, these advantages have not been translated into better glycemic control (3) or into enhanced prevention of chronic complications in children with diabetes. The only benefit demonstrated in children studied in clinical trials was a small reduction in the incidence of nocturnal hypoglycemia (4). Despite of this, glargine is one of the most prescribed drugs for the treatment of diabetes (5). In Brazil, access to health services and medication is a right assured by law. Furthermore, in this country glargine costs over four times more than NPH insulin (R\$ 109.65 against R\$ 23.97 a the $3 \mathrm{~mL}$ ampoule) (6). The study by Rollin and collaborators emerges from this background and is as a source of local (Brazilian) data.

Rollin and collaborators aimed to compare the efficacy and safety profile of glargine (compared to NPH insulin) in children with TIDM younger than eight years old. The endpoints chosen to measure these effects were glycosylated hemoglobin $\left(\mathrm{HbA}_{\mathrm{lc}}\right)$ and mean hypoglycemic events per patient-period, for efficacy and safety, respectively.

To access these endpoints, the Authors used a non-randomized design and compared the patients before and after the use of glargine (1). This type of design (quasiexperimental with historical self-control) is prone to many biases. A randomized design would be methodologically more adequate to answer the question raised in the study. If the small number of patients in the institution was a limiting issue, this could have been overcome by means of adopting a cross-over design or, more appropriately, by means of a multicenter study effort. Furthermore, patients, physicians providing care, and investigators were not blinded, which could contribute to measurement bias. Also, this could lead to an intervention bias: better glycemic control secondary to closer monitoring or stricter therapy adjustment. Another fundamental issue in this trial is how follow-up of these patients took place. The group of 30 children was evaluated at baseline, then treated intensively for 3 months with NPH insulin, and next switched to glargine therapy for 12 months. In this kind of design, a better glycemic control (lower $\mathrm{HbA}_{\mathrm{lc}}$ and less hypoglycemia) over time can occur due to educational gains of patients and parents about disease, and physician-family-patient amelioration of
${ }^{1}$ Unidade de Tireoide, Serviço de Endocrinologia, Hospital de Clínicas de Porto Alegre, Porto Alegre, Brasil 2 Serviço de Patologia Clínica, Hospital de Clínicas de Porto Alegre, Porto Alegre, Brasil

Correspondence to: José Miguel Dora Serviço de Patologia Clínica, Hospital de Clínicas de Porto Alegre

Ramiro Barcelos, 2.350 90035-003 - Porto Alegre, RS, Brasil

jmdora@gmail.com

Received on Oct/9/2009 Accepted on Nov/30/2009 
treatment. The patients were followed monthly during the first 3 months, and then on a every 3 -month basis. The only period in which the follow-up of patients under the NPH insulin and the glargine treatments were comparable was the first 3-month period.

To assess the glycemic control achieved by the two drugs the Authors compared $\mathrm{HbA}_{\mathrm{lc}}$ values from before starting glargine with values achieved along the oneyear glargine treatment.

It is difficult to understand why the Authors used the mean baseline $\mathrm{HbA}_{\mathrm{lc}}(8.68 \%)$ plus the end of the 3 -month NPH treatment $\mathrm{HbA}_{\mathrm{lc}}$ (the so called "NPH -3 and 0 " [8.44\%]) (1), instead of using the on-study$\mathrm{NPH}-\mathrm{HbA}_{\mathrm{lc}}$ values (not directly provided by the Authors) to assess the treatment effect of NPH insulin. On the other hand, the effects of glargine were evaluated using only the on-study-glargine- $\mathrm{HbA}_{\mathrm{lc}}$ values. We calculated $\mathrm{HbA}_{\mathrm{lc}}$ at the end of the 3-month $\mathrm{NPH}$ treatment $(8.20 \%)$ and redesigned the "table 1 " provided the article (1) (Table 1 ).

Despite all the methodological limitations pointed out for the study of Rollin and collaborators (1), the fact that each individual was used as their own control and that a short period of time elapsed between the two treatments (NPH insulin and glargine) makes it possible to draw some conclusions about the comparison of the two treatments.

In order to compare one must take into account the bias imputed to the data and, of course, use data from treatments of same length for each therapy (Figure 1). Using this approach, despite all the contrary bias, NPH insulin provided a better glycemic control of diabetes at the end of the 3-month period when compared to glargine in the same period $\left(\mathrm{HbA}_{\mathrm{lc}}\right.$ of $8.20 \%$ vs. $8.94 \%$, $\mathrm{p}=0.02$ - for $\mathrm{NPH}$ insulin $v$ s. glargine, respectively). At the end of the three months, the difference in $\mathrm{HbA}_{\mathrm{lc}}$ between the two treatment regimens was of $-0.74 \%$ (CI95\%: $-0.11 \%$ to $-1.37 \%, \mathrm{p}=0.02$ ), in favor of $\mathrm{NPH}$ insulin - Table 1 and Figure 1).

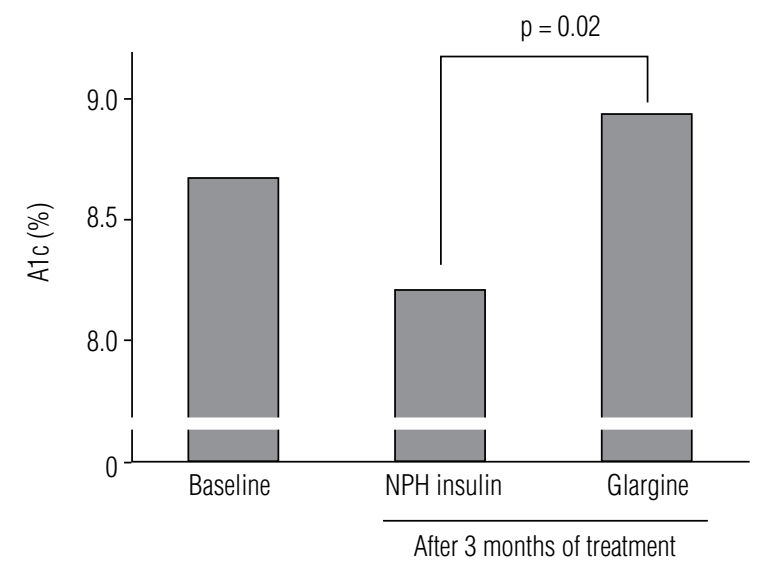

Figure 1. $\mathrm{HbA}_{1 \mathrm{c}}(\%)$ values at baseline, after 3-month NPH insulin treatment, and after 3-month Glargine treatment. Treatment and baseline $\mathrm{HbA}_{1 \mathrm{c}}(\%)$ values compared were not statistically significant for both treatments.

As in the efficacy analysis, safety analysis is extremely bias-limited and some epidemiologic-behavioral phenomena need to be acknowledged in this regard.

The comparison of hypoglycemic episodes occurs in two different follow-up periods: 1) intensive NPH insulin period, when patients were adjusting their insulin dosages; 2 ) glargine period (following the intensive $\mathrm{NPH}$ insulin period), when patient hypoglycemia profile, resistance to insulin and insulin requirements were also known by family and physicians. This can explain the differences between NPH insulin and glargine, regarding hypoglycemic episodes. Furthermore, as mentioned above, the period of time in which patients were using glargine was four times greater than the length of $\mathrm{NPH}$ insulin therapy. In this setting, education gains and a possible dilution of hypoglycemic episodes may have occurred. It would be interesting to know what were the insulin doses and hypoglycemic rates during the three months for both treatment regimens, since in this period patients had the same time to adjust to the new treatment, and were submitted to the same followup regimen.

Table 1. Mean $\mathrm{HbA}_{1 \mathrm{c}}$ throughout the study (redesigned from Rollin and collaborators)

\begin{tabular}{|c|c|c|c|c|c|c|c|}
\hline $\begin{array}{l}\text { Author's } \\
\text { denomination }\end{array}$ & Not available & Not available & $\begin{array}{c}\text { NPH } \\
\text { (-3 plus } 0 \text { months })\end{array}$ & $\begin{array}{l}\text { Glargine } \\
\text { (3 months) }\end{array}$ & $\begin{array}{l}\text { Glargine } \\
\text { (6 months) }\end{array}$ & $\begin{array}{l}\text { Glargine } \\
\text { (9 months) }\end{array}$ & $\begin{array}{l}\text { Glargine } \\
\text { (12 months) }\end{array}$ \\
\hline $\begin{array}{l}\text { Proposed } \\
\text { denomination }\end{array}$ & Baseline & 3 months on NPH & $\begin{array}{c}\text { Baseline and 3-month } \\
\text { NPH means }\end{array}$ & $\begin{array}{l}3 \text { months on } \\
\text { glargine }\end{array}$ & $\begin{array}{l}6 \text { months on } \\
\text { glargine }\end{array}$ & $\begin{array}{l}9 \text { months on } \\
\text { glargine }\end{array}$ & $\begin{array}{l}12 \text { months on } \\
\text { glargine }\end{array}$ \\
\hline $\mathrm{HbA}_{1 \mathrm{c}}(\%)$ & 8.68 & $8.20^{*}$ & 8.44 & 8.94 & 9.19 & 8.91 & 8.64 \\
\hline
\end{tabular}

* Not provided by the authors, calculated based on baseline values, and baseline and 3-month NPH values (proposed denomination).

3 months on NPH insulin vs. 3 months on glargine $=-0.74(C 195 \%-0.11$ to -1.37$), p=0.02$, in favor of NPH insulin. 
Another important aspect related to the safety profile of glargine is the recent report of a possible association between its use and higher cancer incidence $(7,8)$. Until this issue is clarified and appropriate long-term safety data on this analog is available, it does not seem worthwhile to use glargine in patients who will need continuous treatment for life.

According to the discussion above we can conclude that the study conducted by Rollin and collaborators presents methodological limitations that preclude the conclusions reached by the Authors. Moreover, glargine and NPH insulin were adequately compared in a recent randomized and controlled trial, which demonstrated that both have the same efficacy in lowering $\mathrm{HbA}_{1 \mathrm{c}}$, and display similar rates of hypoglycemic episodes (3). Not failing to remember the Hyppocratic Oath taken: "primum non nocere", instead of glargine, NPH insulin (a drug that is very similar in efficacy and has long-term safety data available) seems to be a more reasonable, first-line approach for children with TIDM.

Disclosure: no potential conflict of interest relevant to this article was reported.

\section{REFERENCES}

1. Rollin G, Punales M, Geremia C, Vissoky G,Tschiedel B. Utilização da insulina glargina em crianças menores de oito anos de idade. Arq Bras Endocrinol Metab. 2009;53(6):721-5.

2. Lepore M, Pampanelli S, Fanelli C, Porcellati F, Bartocci L, Di Vincenzo A, et al. Pharmacokinetics and pharmacodynamics of subcutaneous injection of long-acting human insulin analog glargine, $\mathrm{NPH}$ insulin, and ultralente human insulin and continuous subcutaneous infusion of insulin lispro. Diabetes. 2000;49(12):2142-8.

3. Chase HP, Arslanian S, White NH, Tamborlane WV. Insulin glargine versus intermediate-acting insulin as the basal component of multiple daily injection regimens for adolescents with type 1 diabetes mellitus. J Pediatr. 2008;153(4):547-53.

4. Deiss D, Kordonouri O, Hartmann R, Hopfenmuller W, Lupke K, Danne T. Treatment with insulin glargine reduces asymptomatic hypoglycemia detected by continuous subcutaneous glucose monitoring in children and adolescents with type 1 diabetes. Pediatr Diabetes. 2007;8(3):157-62.

5. Holleman F, Gale EA. Nice insulins, pity about the evidence. Diabetologia. 2007;50(9):1783-90.

6. Consulta remédios [database on the Internet]. 2009. Accessed on: 2009 September 15. Available from: http://www.consultaremedios.com.br/

7. Hemkens LG, Grouven U, Bender R, Gunster C, Gutschmidt S, Selke GW, et al. Risk of malignancies in patients with diabetes treated with human insulin or insulin analogues: a cohort study. Diabetologia. 2009;52(9):1732-44.

8. Smith $U$, Gale EA. Does diabetes therapy influence the risk of cancer? Diabetologia. 2009;52(9):1699-708. 